\title{
Red toenails
}

$\mathrm{T}$ oday, I am down and depressed. The university examinations for first-year students have started. Twenty-six youngsters appear for each day's exercise, which involves histology spot identification stations, discussions on dissected specimens, surface anatomy and viva voce. The day can be long and tiresome: standing for no less than five hours, examining student after student, without showing frustration at stupid gaffes, anger at gross errors or impatience with juvenile behaviour. Plus the tension of hosting two senior visiting examiners from other universities, who can, at times be very demanding, with candidates sometimes paying the penalty by way of underperformance, under pressure.

But these were not the things that upset my composure. In fact, everything went off better than anticipated, and the students did their practical and viva quite proficiently. What suddenly unnerved me was that, during the surface anatomy exercise, one of four cadavers on the cold steel dissection table was that of a young female.

The Anatomy Act requires that all individual identifiers be erased before the cadaver is used in medical colleges. Toward this end, each is stripped bare,

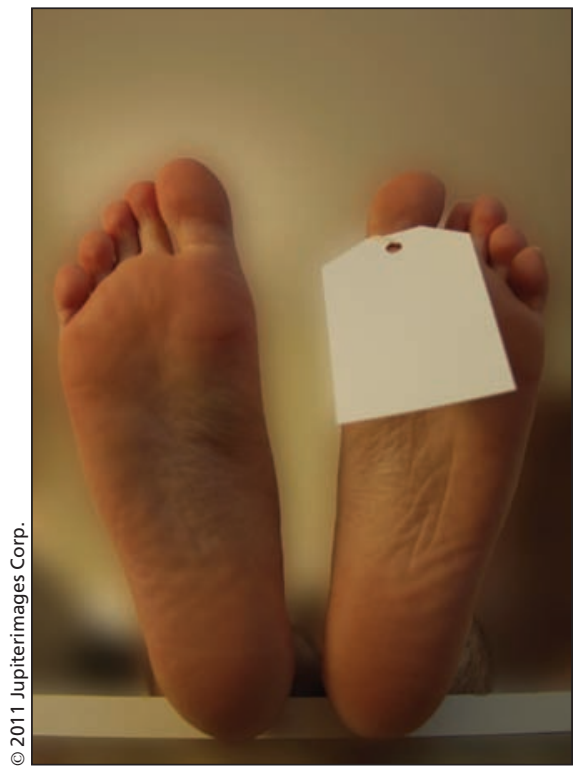

I gave an examinee student her assignment, "surface mark the dorsalis pedis artery." This blood vessel runs on the dorsum of the foot, dipping away into the gap between the first and second toes to the sole. Considered quite significant by surgeons, its pulse can be felt, giving readable clues on the state of circulation, blood pressure or temperature, all of which are useful clinical signs for differential diagnosis in various disease processes. The dorsalis pedis has other

\section{The sight of the bright crimson nail polish on the young dead girl was terribly disconcerting}

shaved clean, eyebrows are removed, and scalp hair is tonsured. Rings, bangles, anything that might give a clue as to who he or she was are eliminated. The cadavers become just odd looking objects, ceasing at times to even look human. This systematic eradication of human identity makes the young medic feel less emotional when dissecting and gives the dissected dead a little more dignity. applied applications, but first year students need to know at least the information mentioned above.

After five minutes, the time usually given for surface marking, I walked over to have a look at the foot of the cadaver on which the candidate had to chalk-mark the course of the artery. The tiny neat foot, with its ankle front showed the linear chalk mark the candidate had drawn.
Something I saw jolted me; the dead woman's toenails, all five of them wore fairly recently painted red polish. Meticulously varnished, each nail was a resplendent scarlet. I could make out it was quite recent, for the colour still gleamed. For me, used as I am to death and dying, the sight of the bright crimson nail polish on the young dead girl was terribly disconcerting. How could this youngster, who had painted her toenails with such care and precision in her hospital bed, be dead and dispensed with so rapidly?

How could she be unclaimed and homeless just days or even hours afterward? Who was she? How could one who valued how she looked and presented herself, even when on a sick bed, be so suddenly unwanted? Had she no kith, kin or claimant? How had she come to be discarded like a destitute person, a burden, a loadstone?

I will never find the answers, never. All trace of the source and identity of unclaimed cadavers sent to the mortuary stand erased. I must live with these questions and try to find reasons why men and women can be so cruel. How can a family vanish, deserting a sick girl at death's door? Was she that lost to society that she deserved to be abandoned; an unclaimed and unwanted nobody in a eerily forbiddingly sterile dissection hall?

This evening, before I left my department I got the cadaver with painted toes removed from the dissection hall's steel table and returned it back into its formalin tank, where, I hope it will lie sunken and unseen, at least till the day I retire from this sickening anatomist's job I do to earn my keep.

\section{Arunachalam Kumar MBBS \\ Dean \\ Faculty of Medicine \\ Nitte University \\ Mangalore, India}

CMAJ 2011. DOI:10.1503/cmaj.091928 